\title{
The Initial Phase of the Argumentative Discussions Between Parents and Children
}

4 This chapter examines the initial phase of parent-child argumentative 5 discussions during mealtime. The conceptual tool adopted for the 6 analysis of the initial phase of parent-child argumentative discussions 7 is based on the pragma-dialectical ideal model of a critical discussion 8 (van Eemeren \& Grootendorst, 2004)! The types of issues leading par9 ents and children to engage in argumentative discussions during mealtime as well as the contribution that parents and children provide to the inception of argumentation are described and discussed. The analysis of the initial phase of parent-child argumentative discussions also considers the role played by the specificity of the parent-child relationship and the distinctive features of the activity of family mealtime for the beginning of an argumentative discussion. Exemplary argumentative sequences that bring to light the results obtained through the qualitative analysis of a larger corpus of argumentative discussions between parents and children are presented and discussed. 


\subsection{Types of Issues Leading Parents and Children to Engage in Argumentative Discussions}

Parent-child mealtime conversations are unpredictable events as they are characterized by substantial-but not total-freedom about the issue that can be tackled (Blum-Kulka, 1997). The topics discussed during mealtime are, in fact, often entirely unforeseen by all family members. However, not all topics are open for discussion at mealtime. For instance, money, politics, and sex are usually viewed as less suitable themes for mealtime conversations, above all in the presence of young children, because even when no guests are present, the presence of children affects the choice of what is acceptable and what can be mentioned at mealtime. The next extract, for example, shows how an Italian mother explicitly invites her husband, who was commenting on a political news item, to move from this topic to a different one because, according to her opinion, politics is not an appropriate topic for mealtime (line 2 and line 4):

\section{Excerpt 3.1}

Swiss family I. Dinner 3. Family members: father (DAD, 41 years), mother (MOM, 38 years), Luca (LUC, 6 years and 8 months), and Luisa (LUI, 3 years and 11 months). All family members are eating, seated at the meal table. DAD sits at the head of the meal table. MOM and LUI sit on the right-hand side of DAD, while LUC sits on their opposite side.

1. *DAD: ma ti rendi conto? ((rivolgendosi a MOM)) but can you believe it? ((talking to MOM))

$\rightarrow \quad$ *DAD: ci sono anche persone che hanno il coraggio di votare uno come questo qui there are even people who have the courage to vote for a person like him

2. *MOM: no no, ora cambiamo argomento no no now we change the subject

3. *DAD: ma hai sentito cosa ha detto oggi? did you hear what he said today? 
4. *MOM: no no, ma ora cambiamo argomento, non parliamo di questo a tavola no no, but now let us change the topic, do not discuss this at the meal table

5. *DAD: ah:: va bene, hai ragione ah:: OK, you are right

Because of the variety of topics discussed by parents and children during mealtime conversations, it is, therefore, crucial to identify the issues leading them to begin an argumentative discussion. Are there specific types of issues leading to argumentation, or parents and children discuss argumentatively on all the topics addressed during mealtime? What emerges through the analysis of the corpus of parent-child argumentative discussions during mealtime is that they unfold around two general types of issues: parental directives and children's requests. In the following sections, how these two different types of issues lead to the beginning of argumentative discussions between parents and children will be described and discussed by means of the presentation of some argumentative sequences.

\subsubsection{Issues Generated by Parental Directives}

In most cases, the issues leading them to engage in argumentative discussions are generated by parental directives. The issues generated by parental directives are strictly bound to the specific situational activity children are involved in, i.e., the activity of mealtimes. In line with previous studies on family mealtime conversations, the issues generated by parental directives frequently concern feeding practices (Arcidiacono \& Bova, 2015; Bova, 2015; Bova \& Arcidiacono, 2015; Capaldi \& Powley, 1990; Delamont, 1995). For example, it is common to observe discussions in which the parents do not want their children to eat a particular food or more than a certain amount of a particular food, or in which the children want to ask for different food (Arcidiacono, 2011; Bova \& Arcidiacono, 2014; Ochs, Pontecorvo, \& Fasulo, 1996). In these situations, as observed by Kent (2012), it is complicated for children to resist parental directives without initiating a dispute. The why and the wherefore of this difficulty can be traced looking at the definition of directives done by Craven and Potter AQ1 


\section{2

(2010). According to these authors, directives embody no orientation to the recipient's ability or desire to perform the relevant activity, and this lack of orientation to ability or desire is what makes them recognizable as directives. In these cases, accusations and related actions assume both a retroactive value because they concern violations (actions on the part of the defendant and oppositional moves) and a proactive one when they are projected to initiate and maintain dispute sequences. The common aspect of these discussions is that in both cases parents and children engage in argumentative discussions around the topic of food and in which they put forward arguments to convince the other party that their standpoint is more valid and therefore deserves to be accepted. The following discussion between a father and his 8-year-old son, Gabriele, offers an illustration of how a parental directive related to feeding practices can trigger the beginning of an argumentative discussion during mealtime:

\section{Excerpt 3.2}

Italian family IV. Dinner 3. Family members: father (DAD, 38 years), mother (MOM, 34 years), Gabriele (GAB, 8 years and 5 months), and Daniele (DAN, 5 years and 4 months). All family members are eating, seated at the meal table. DAD sits at the head of the meal table. MOM and GAB sit on the left-hand side of DAD, while DAN sits on their opposite side.

\section{\%sit: *GAB sta bevendo una bibita gassata} $G A B$ is drinking a soft drink

1. *DAD: basta bere $X X X$ ((nome della bibita gassata)) Gabriele! stop drinking $X X X$ ((name of the brand of the soft drink)), Gabriele!

$\rightarrow \quad$ *DAD: adesso ti do il riso. now I will give you some rice.

2. ${ }^{*} \mathrm{GAB}$ : no, non voglio altro: ((sedendosi sulla sedia)) no, I do not want anything else: ((sitting on the chair))

$\rightarrow \quad *$ GAB: $\quad$ per favore, niente. [:! facendo cenni di negazione col capo]

3. *DAD: no:: non hai mangiato abbastanza. no:: you have not eaten enough.

4. *GAB: no:::

no:::

$\rightarrow \quad * G A B: \quad$ no:: sono pieno:

no:: I am full: 


\section{\%act: $\quad$ GAB guarda verso DAD e inizia a bere nuovamente la bibita gassata} $G A B$ looks towards $D A D$ and starts drinking the soft drink again

5. *DAD: ti ho detto:: Gabriele basta bere questa roba ((la bibita gassata) I told you:: Gabriele stop drinking this stuff ((the soft drink)) \%act: $\quad$ DAD prende il bicchiere di GAB e lo porta in cucina

$\begin{array}{ll}\text { \%act: } & \text { GAB guarda verso DAD e inizia a bere nuovamente la bibita } \\ & \text { gassata } \\ & \text { GAB looks towards DAD and starts drinking the soft drink again } \\ & \text { ti ho detto:: Gabriele basta bere questa roba ((la bibita gassata) } \\ & \text { I told you:: Gabriele stop drinking this stuff ((the soft drink)) } \\ & \text { DAD prende il bicchiere di GAB e lo porta in cucina } \\ & \text { DAD takes GAB's glass and takes it to the kitchen }\end{array}$

The excerpt is opened, in line 1, by a father's directive that can be interpreted as implicitly condensing a standpoint and a justification. In the analytical reconstruction of argumentation, the father's claim concerns an invitation to the child ("you should eat some food"), followed by a justification ("because you are drinking too much"). It is in line 2 when a difference of opinion between Gabriele and his father arises. The child's intervention constitutes the beginning of the argumentative discussion, as the child replies to the father that he does not want to eat anything else. From an argumentative perspective, what is interesting is the fact that Samuele does not consider that he must stop drinking, but immediately focuses on the main claim of the parent, i.e., to convince the child to eat the rice. Gabriele's refusal to accept his father's proposal determines the orientation of the discussion exclusively around the food. The father ratifies this specific direction of the argumentative discussion in line 3 , as he advances an argument based on the quantity of food (no:: you have not eaten enough). However, as we can observe from Gabriele's answer in line 4, this argument is not effective enough to convince the child to accept the father's standpoint. The opposition by Gabriele ("no::: no:: I am full") determines a change of strategy in the father's position. The adult turns back to the first directive (to stop drinking) to make explicit the fact that Gabriele cannot discuss the parental issue anymore. The father's directive is advanced again using the expression "I told you:: Gabriele," in line 5, and through the action of taking the soft drink away from Gabriele. From the father's perspective, this last intervention is a way to reconduct the discussion to the first level, giving as an argument the inappropriate conduct of Gabriele who is drinking instead of eating. What could be interpreted as an imposition could turn out to be a constructive move aiming at 


\section{4 A. Bova}

teaching the value of argumentation as a rational way to solve differences of opinion. The analytical overview of the argumentative discussion between the child, Gabriele, and his father is summarized below:

Issue

Standpoints

(DAD)

$(G A B)$

Argument

$(\mathrm{GAB})$
Should Gabriele eat some rice?

Yes, you must

No, I do not want to

You have not eaten enough

I am full

Parents and children frequently engaged in argumentative discussions because of parental directives related to having to eat a particular food. Other examples of parental directives related to feeding practices triggering the beginning of an argumentative discussion during mealtime between parents and children include: Should Stefano eat the rice? Should Manuela eat the meat? Should Silverio eat the salad? Should Gabriele eat the tortellini? These results are in line with previous studies on family discourse at mealtimes (Bova \& Arcidiacono, 2018; Wiggins \& Potter, 2003). However, parental directives did not pertain exclusively to feeding practices, but also, frequently, the teaching of correct table manners. The following example, a discussion between a mother and her 8-yearold son, Gabriele, clearly illustrates these dynamics:

\section{Excerpt 3.3}

Italian family IV. Dinner 2. Family members: father (DAD, 38 years), mother (MOM, 34 years), Gabriele (GAB, 8 years and 5 months), and Daniele (DAN, 5 years and 4 months). All family members are eating, seated at the meal table. DAD sits at the head of the meal table. MOM and DAN sit on the left-hand side of DAD, while GAB sits on their opposite side.

\%act: $\quad$ GAB si alza da tavola e sta per andare a sedersi sul divano $G A B$ gets down from the meal table, and he is about to go and sit on the couch

1. *MOM: Gabriele, non puoi andare a guardare la TV sul divano Gabriele, you cannot go to watch TV on the couch

\%act: $\quad$ GAB torna a sedersi a tavola GAB comes back to sit at the meal table 2. *GAB: ma io voglio guardare la TV sul divano! 
but I want to watch TV on the couch!

3. *MOM: Gabriele, quando si mangia non ci si alza da tavola Gabriele, during mealtimes you cannot get down from the meal table

4. *GAB: perché no?

why not?

5. *MOM: perché è maleducato farlo

because it is ill-mannered to do it

${ }^{*} \mathrm{GAB}: \quad \mathrm{mmm}$

$m m m$

\%act: $\quad G A B$ continua a mangiare rimanendo seduto a tavola $G A B$ remains seated at the meal table and continues to eat

This sequence starts with the child, Gabriele, who leaves the meal table and is about to go and sit on the couch to watch TV. The mother disagrees with her son's behavior and makes her standpoint explicit in line 1 (Gabriele, you cannot go to watch TV on the couch). However, the adult's directive, in its actual form, does not provide any reasons. Gabriele interprets the fact that he is not allowed to go watch TV as a directive against his wish. In fact, in line 2, the child, who came back to sit at the meal table, disagrees with his mother and advances his standpoint using the adversative conjunction "but" to mark the different position concerning the adult statement (but I want to watch TV on the couch!). In argumentative terms, the sequence that goes from line 1 to line 2 represents the confrontation stage of the ideal model of a critical discussion, as the mother's standpoint meets with the child's opposition. In this phase of the discussion, the issue leading the mother to engage in an argumentative discussion with her son is related to the teaching of correct table manners. However, to understand the issue discussed in the presented sequence, the circumstances in which the argumentation takes place must be considered. In the present case, the possibility of watching TV is not a topic of discussion per se, but it is the fact that family rules, at least for this family, imply finishing dinner before going engaging in other activities (including watching TV on the couch). The implicit accusation made by Gabriele (the impossibility of going to watch TV despite his wish, "I want...") requires the parent to give a justification. The discursive interventions by Gabriele have played a crucial role in this sense since 
his mother has been challenged to defend her standpoint. In other words, the mother has been forced, by Gabriele, to specify the reasons of her directive (line 3: Gabriele, during mealtimes you cannot get down from the meal table). The question is whether and how the participants use the potential of dissent to handle the critical question argumentatively. Finally, after the unilateral directive, the mother, in line 5, offers a strong dissent preventing the possibility of continuing the debate (because it is ill-mannered to do it). As already Gruber (2001) put it, in family conversations, when social rules are violated or fail to meet expectations, an argumentative discussion can occur with the aim to solve situational accusations.

The reconstruction of the argumentative discussion between the child, Gabriele, and his mother is summarized below:

Issue

Standpoints

Argument
Can Gabriele watch TV on the couch during mealtime?

(GAB) Yes, I can

(MOM) No, you cannot

(MOM) Because it is ill-mannered to do it

The issues leading parents to engage in argumentative discussions with their children were generated by parental directives that pertain also to the behavior of children in social interactions outside the family. The following example is an illustration of how an issue related to the child's behavior in the school context leads a father to engage in an argumentative discussion with his 8-year-old son, Silverio:

\section{Excerpt 3.4}

Italian family I. Dinner 3. Family members: father (DAD, 38 years), mother (MOM, 38 years), Silverio (SIL, 8 years), and Gabriele (GAB, 5 years and 4 months). All family members are seated at the meal table. $\mathrm{DAD}$ sits at the head of the meal table. MOM and GAB sit on the right-hand side of DAD, while SIL sits on their opposite side.

1. *SIL: oggi, la maestra non mi ha fatto andare al bagno today, the teacher did not let me go to the bathroom

2. *DAD: devi ascoltare le regole della maestra! you must listen to the teacher's rules! 
3. *SIL: perché diceva, che possiamo andare solo alla fine della lezione because she said, that we can only go at the end of the lesson

$\rightarrow \quad$ *SIL: $\quad$ quando: suona la campanella when: the bell rings

$4 \quad$ *DAD: e tu cosa hai fatto? and what did you do?

5. *SIL: io le ho detto che non era giusto I told her that it was not right

6. *DAD: non devi rispondere male alla maestra, devi ascoltare quello che ti dice! you should not talk back to the teacher, you must listen to what she says!

7. *SIL: ma io dovevo andare in bagno but I had to go to the bathroom

8 *DAD: è maleducato rispondere alla maestra, lo sai? it is bad manners to talk back to the teacher, you know?

9. $\quad$ SIL: si, lo so. yes, I know.

10. *DAD: e allora non lo fare più! so do not do it anymore!

11. *SIL: $\quad \mathrm{mmm}::$ ((con un'espressione triste)) $m m m::$ ((with a cheerless expression on his face))

The sequence begins with the child, Silverio, who is telling his father that at school that day, the teacher had not permitted him to go to the bathroom. In line 2 , the father immediately makes his standpoint explicit, telling Silverio that he must follow the teacher's rules, thus opposing the child's standpoint. The father is not asking Silverio to account for the teacher's prohibition. He is immediately appealing to the authoritative role of the teacher to reply to the child. The father's position is orienting the exchange toward the rule that the teacher's directions must be respected. In line 3 , Silverio provides the reasoning that the teacher used to justify the prohibition ("because she said, that we can only go at the end of the lesson"). The father seems to be more interested in finding out how his son behaved ("and what did you do?") than in judging the reasoning underlying the teacher's prohibition. This intervention opens the ground for the child to add some elements in support of his initial complaint about the prohibition of the teacher. It is a way to enlarge Silverio's response duties, calling him to argue on an equal footing with his father. Silverio can 
express his point of view concerning the teacher's veto. In line 5, the child tells his father that he told the teacher that the prohibition was, according to him, not right.

However, the father continues to show more interest in the argument advanced by the teacher than in his child's opinion about the prohibition. In line 6, the father explicitly disapproves his son's behavior ("you should not talk back to the teacher, you must listen to what she says"), appealing to a general rule at school, i.e., that it is not possible to disagree with the teacher's directives. By doing so, the father is recalling the rule positioned at the beginning of the sequence, asking the child to align with his argument based on the authority of the teacher. The father's intervention can be interpreted as an opposition turn involving a comment upon what was said in the prior turn, but the appeal to the general assumption and principle connected to the institutional value of the teacher's role can also be intended as a way of avoiding further discussions. Following the father's orientation, there is no way to debate the teacher's rules at school. However, the intervention by the child, Silverio, in line 5, puts the father in the position to add some further arguments sustaining his standpoint. Moreover, by his intervention in line 7 ("but I had to go to the bathroom"), the child starts to repair a potential misunderstanding (his physiological need instead of the choice of answering back the teacher).

The argumentative discussion between the child, Silverio, and his father is particularly interesting because there is a confrontation stage where the father's standpoint (you must listen to the teacher's rules) meets with the child's opposite view (I told the teacher that it was not right). By focusing on this phase of the discussion, we can highlight that the issue leading the father to engage in an argumentative discussion with his son is related to the behavior of the child in the school context, and not to the appropriateness of the teacher's prohibition. The child, Silverio, tries to justify his reaction on the assumption that the teacher's prohibition was not right, while the father uses the argument of authority ("it is bad manners to talk back to the teacher, you know?") to underline that at school it is not possible to disagree with the teacher's directives. In this sense, we can observe how during mealtime family members 
256 can deny the opponent's status/behavior by challenging the position 257 put forward in the confrontation stage. In line 10, the father ends the 258 sequence ("so do not do it anymore!") by commanding Silverio not 259 to repeat the same mistake in the future. The father's final statement 260 suspends the topic as a subject of discussion: the pragmatic device "so" 261 presents his position as a generally accepted norm that is not open to 262 discussion. The child accepts this intervention of the father, although with a cheerless expression on his face. In agreement with what

264

265

266 Goodwin (2006) already observed analyzing a dispute between a father and his son who is just entering adolescence, in the argumentative discussion between the child, Silverio, and his father it seems that both parties, in their orientation to future actions, are willing to negotiate in a macro-perspective, i.e., the future behavior of Silverio at school. We can reconstruct the argumentative discussion between the child, Silverio, and his father, as follows:

Issue

Standpoints

(SIL)

(DAD)

Argument

(SIL)

(DAD)
Does Silverio have to respect the teacher's rule? The teacher's rule was not right You must listen to what the teacher says But I had to go to the bathroom It is ill-mannered to answer back the teacher

The argumentative discussion between the child, Silverio, and his father, is not the only case of argumentative discussion triggered by an issue related to the social behavior of children. Other issues leading to argumentative discussions between parents and children related to the same type of issues are, for example, the following: Should Giorgia invite all her schoolmates to her birthday party? Should Francesco apologize with his schoolmate Antonio? Should Manuela lend her crayons to her friend Valentina?

\subsubsection{Issues Generated by Children's Requests}

The second type of issues leading parents and children to engage in argumentative discussions were generated by children's requests. This type of issues concerns activities not only related to mealtimes, such as 
eating behaviors and teaching of correct table manners by parents, but also to children's social behavior within and outside the family context. In particular, one question asked by children to their parents, more than others, seems to have a significant role from an argumentative perspective: the Why-question. ${ }^{1}$

Children's Why-questions have long held the attention of many scholars in diverse research fields, but above all in developmental and cognitive psychology and linguistics. The first studies date back to the early twentieth century. Stern (1924), who was interested in investigating the essential sides of children's minds as they develop as far as their sixth year, in his seminal work "Psychology of early childhood" divided the development stages in which questions usually emerge into two periods. The first, named naming period, concerns the names of objects and occurs at the end of children's second year. During this period, the questions that children produce refer to objects that are present or to actions related to an ongoing activity. The second period, named when and why period, typically occurs between 3 and 4 years. In this period, children begin to form questions about absent objects or people, or events with no immediate connection with the present. According to Piaget (1929) however, children begin to ask Why-questions because of a specific developmental need. He observed that children ask questions - in particular, Why-questions - to obtain more information to fill gaps in their knowledge. Following Piaget, Isaacs (1930) argued that the need to ask Why-questions arose when the child must deal with anomalies, deviations, contrasts, or differences which stimulate a sense of unease or unsettledness.

More recent studies have shown that the ability of children to answer as well as ask Why-questions, and to clarify the reasons on which their answers are based, increase rapidly between the ages of 2 and 5 years (Loukusa, Ryder, \& Leinonen, 2008; Valian \& Casey, 2003). This aspect plays a vital role in the development of children's verbal

\footnotetext{
${ }^{1}$ In Italian, the word "perche" is used both to ask "why" and as a response, like the English word "because." In attempting to identify all Why-questions asked by children to their parents, I did not consider each instance of "perché" used by children when speaking with their parents but only those with an interrogative function.
} 
314 skills and therefore in their capacity to interact with adults and peers. According to Chouinard, Harris, and Maratsos (2007, p. vii), "asking questions allows children to gain information they need to move their knowledge structures closer to an adult-like state." By focusing on preschool-aged children (aged 2-5 years), the authors observed that when parents do not provide, or cannot provide satisfactory answers to a child's question, the child perseveres in asking his/her question to gain the requested information. Chouinard and her colleagues also observed that during the development children learn to formulate Why-questions more efficiently to gather the information they want to find out. In the authors' view, the ability to ask this type of questions constitutes an efficient cognitive development mechanism. In a recent work focused on preschool children aged 2-4 years, Frazier, Gelamn, and Wellman (2009) examined children's Why-questions and their reactions to the answers they received in conversations with adults. Like what was found by Chouinard et al. (2007) and Bova and Arcidiacono (2013), they observed that children agree and ask further questions following adult explanations. On the contrary, children keep asking Why-questions and provide their explanation following inadequate or nonexistent explanations by parents.

Altogether, this concise review of the most relevant literature on children's Why-questions indicates that what drives children to ask Why-questions to their parents is primarily the need to acquire new information. In most cases, the studies so far realized bring attention to the explanatory function of children's Why-questions, i.e., how this type of question allows children to ask for knowledge of the reasons that have caused an event. Hitherto, less attention has been paid to the argumentative function of children's questions, i.e., the action of putting into doubt the standpoint advanced by another person.

Concerning the specific role of Why-questions, Walton (2004, p. 72) well explains the difference between the argumentative and explanatory function of Why-questions. The explanatory Why-questions aim to gain an understanding of the causes of an event already ascertained and acknowledged by discussants. The explanation moves from an ascertained fact and aims not to justify—as facts require no justification—but 


\section{A. Bova}

to identify the reasons why the fact is true, or the event occurred. In contrast, the argumentative Why-questions presuppose a difference of opinion between two or more parties, as argumentation starts from a controversial thesis, and ideally ends with conclusive proof ${ }^{2}$. In line with the previous studies on children's Why-questions, in most cases, the children asked Why-questions to their parents to acquire an explanation of an event with an immediate connection to the present. The explanatory function of the Why-question can be clearly observed, for example, in the following dialogue between a father and his 6-year-old son, Francesco:

\section{Excerpt 3.5}

Swiss family V. Dinner 2. Family members: father (DAD, 37 years), mother (MOM, 37 years), Francesco (FRA, 6 years and 3 months), and Michele (MIC, 4 years and 2 months). All family members are eating, seated at the meal table. DAD sits at the head of the meal table. MOM and MIC sit on the right-hand side of DAD, while FRA sits on their opposite side.

1. *FRA: papà, perché non piove oggi?

Dad, why is not it raining today?

2. *DAD: perché oggi, le nuvole sono piene d'acqua because today, the clouds are full of water

$\rightarrow \quad$ *DAD: $\quad$ ma la vogliono tenere tutta per loro, ancora un po'! but they want to keep it just for themselves, a little longer!

This sequence starts with the child, Francesco, who notes, looking out the window, that, unlike previous days, it is not raining. The child, in line 1 , asks his father why it is not raining. Through his straightforward question, the child seeks to know the cause of a nonevent. In responding to his child's Why-question, the father, in line 2, provides an explanation, adapting the content and language of his answer to the child's level of understanding. It is important to observe that there is not a difference of opinion between father and child, as they both agree that the event, i.e., today is not raining, is true.

\footnotetext{
${ }^{2}$ For a detailed study on the differences between argumentation and explanation, see also Rigotti and Greco Morasso (2009) and Snoeck Henkemans (1999, 2001).
} 
Another example that allows us to clarify the explanatory function of children's Why-question further is the following dialogue between a mother and 6-year-old daughter, Giorgia:

\section{Excerpt 3.6}

Italian family II. Dinner 3. Family members: father (DAD, 34 years), mother (MOM, 33 years), Giorgia (GIO, 6 years and 6 months), and Clara (CLA, 3 years and 10 month). All family members seated at the meal table. DAD sits at the head of the meal table. CLA sits on the lefthand side of DAD, while GIO plays with MOM seated on MOM's legs.

\%act: $\quad$ GIO gioca con MOM seduta sulle gambe di MOM GIO plays with MOM seated on MOM's legs

1. *MOM: Alessia è coccolata da tutti a scuola ((scuola materna)) Alessia is coddled by everyone at school ((kindergarten))

2. *GIO: perché è coccolata da tutti? why does everyone coddle her?

3. *MOM: perché è piccola [: ridendo]

4. $\quad$ *MOM: $\quad$ è proprio piccola [: ridendo] she is really a baby [: laughing]

\%act: $\quad$ MOM e GIO ridono

5. *MOM: $\quad$ non è vero?

MOM and GIO laugh

This sequence starts, in line 1, with the mother saying to her older daughter, Giorgia, that everyone at kindergarten coddles her young sister, Clara. In the meanwhile, Clara is playing seated on her mother's legs. The mother's expression appears to be a way to keep playing with her young daughter. Giorgia, in line 2, replies to her mother by advancing a request of explanation: Why does everyone at kindergarten coddle Clara? In this case, there is no difference of opinion between the mother and her older daughter Giorgia. In fact, by asking a Whyquestion, Giorgia is not casting doubt on the fact that everyone at kindergarten coddles her younger sister, but she manifests her interests to know why. As in the previous example, i.e., the dialogue between the 

child, Francesco, and his father, also in this case the parent's standpoint is not put into doubt by the child.

In the corpus, children asked Why-questions not only to know the reasons of events already ascertained but also to put into doubt the validity of the reasons on which the parents' opinions are based. The Why-questions characterized by an argumentative function were less frequently observed than those with an explanatory function. Typically, this second type of children Why-questions were followed by arguments advanced by parents which justify their opposition to the child's standpoint. An example that illustrates this aspect is the following dialogue between the 7-year-old daughter, Manuela, and her father:

\section{Excerpt 3.7}

Swiss family III. Dinner 1. Family members: father (DAD, 39 years), mother (MOM, 34 years), Manuela (MAN, 7 years and 4 months), Filippo (FIL, 5 years and 1 month), and Carlo (CAR, 3 years and 1 month). All family members are eating, seated at the meal table. DAD sits at the head of the meal table. MOM and CAR sit on the left-hand side of DAD, while FIL and MAN sit on their opposite side.

1. *MAN: questo poco di pasta lo posso lasciare? ((sollevando leggermente il suo piatto per mostrarne il contenuto al papà)) can I leave this little bit of pasta? ((slightly raising the plate to show the contents to the father))

Here the expression this little bit aims to obtain a concession. The father, on the contrary, replies with a prohibition:

2.

2. no, non puoi no, you cannot

At this point, Manuela, interested in challenging the parental prohibition, asks:

3.
*MAN: perché papà? why Dad? 
In his answer, the father rebuts the daughter's argument based on this little bit:

4.

*DAD:

non ne hai mangiato per niente, Manuela you have eaten nothing, Manuela

In this dialogue, there is a difference of opinion between the child, Manuela, and her father. Manuela wants to leave a little bit of pasta that is still on her plate, while the father, in line 2, disagrees with her daughter ("no, you cannot"). By asking a Why-question, in line 3, the child challenges her father to justify the reasons on which his prohibition is based. At this point, in line 4, the father puts forward an argument in support of his standpoint ("you have eaten nothing, Manuela"). We can reconstruct the argumentative discussion between the child, Manuela, and her father as follows:

Issue

433

Can Manuela leave a little bit of pasta (and not eating all of it)?

Standpoints (MAN) Yes, I can

(DAD) No, you cannot

Argument (DAD) You have eaten nothing

The following dialogue between the 4-year-old child, Alessandro, and his mother is a good illustration of an additional feature of children's Why-questions with an argumentative function:

\section{Excerpt 3.8}

Swiss family IV. Dinner 1. Family members: father (DAD, 36 years), mother (MOM, 34 years), Stefano (STE, 8 years and 5 months), and Alessandro (ALE, 4 years and 6 months). DAD sits at the head of the meal table, MOM and STE sit on the left-hand side of DAD, while ALE is walking around the meal table.

\% sit: $\quad$ ALE tocca e guarda il contenitore delle medicine ALE touches and looks at the container with the medicine

1. *ALE: $\quad$ io: me la prendo una di queste qui (pillole).
I am: going to take one of these (pills). 
$\rightarrow \quad *$ ALE: $\quad$ si!

2. *MAM: non puoi, Alessandro!

you cannot, Alessandro!

3. *ALE: che?

\section{what?}

4. *MOM: non puoi. [:! scuote la testa]

you cannot. [:! shakes his head]

5. *ALE: perché no?

why not?

6. *MOM: perché i bambini, devono prendere delle medicine speciali because children, have to take special medicine

$\rightarrow \quad$ *MOM: $\quad$ non possono prendere le medicine degli adulti they cannot take medicine for adults

$\rightarrow \quad$ *MOM: $\quad$ altrimenti, si sentono male. otherwise, they will get sick.

The sequence begins when the child, Alessandro, tells his mother of his intention to take the pills from the medicine container. The child announces his action with a pre-sequence - I am going to..." - and reinforces his position by concluding his remark with "yes" (line 1). The mother disagrees with the child's behavior, twice repeating, in line 2 and line 4, "you cannot." After, in line 5, Alessandro asks his mother why he cannot take the pills from the medicine container ("why not?"). In doing so, the child makes no effort to defend his position by putting forward arguments on his behalf; instead, he challenges his mother to explain why he cannot take the pill from the medicine container. The mother, in line 6, does not avoid justifying her prohibition, putting forward her argument: "because children have to take special medicine." The subject of the mother's claim is no longer her son, but the broader category of children, "they cannot take [...] they will get sick." Accordingly, this intervention evokes a general rule-children have to...- - to which Alessandro is also subject.

In this dialogue, we can observe a difference of opinion between the child, Alessandro, and his mother, since they have two opposing standpoints. Through his Why-question, Alessandro makes it clear that he wants to know the reason why he cannot take the pills from the medicine container, i.e., the reason for the prohibition imposed by his mother. From an argumentative perspective, by asking a Why-question, the child assumes a waiting position before accepting or putting into 
468 doubt the parental directive. As a matter of fact, by asking a Why469 question, the child challenges his mother to justify her standpoint. 470 Moreover, the child shows his desire to find out the-often implicit471 reasons on which his parents' standpoint is based. Accordingly, the Why-question reflects Alessandro's desire to know and find out what is, until that point, unknown to him. The reconstruction of the argumentative discussion between the child, Alessandro, and his mother is summarized below:

Issue Can Alessandro take the pills from the medicine container?

Standpoints (ALE) Yes, I can (MOM) No, you cannot

Arguments (MOM) a) Because children cannot take medicine for adults

Other examples of issues leading to argumentative discussions between parents and children triggered by children's requests include: Can Alessandro use that eraser? Can Dad sing along with Marco? Can Alessandro take the crayon? Can Francesco whisper in his Dad's ear?

\subsection{Parents' and Children's Contribution to the Beginning of Argumentative Discussions}

This chapter has been devoted to the investigation of the initial phase of parent-child argumentative discussions. We have seen the argumentative discussions unfold around issues that are generated by parental directives and children's requests. Parental directives often concern activities related to mealtime, such as having to eat a particular food or adopting correct table manners, while children's requests refer to a wide range of topics, from issues closely related to mealtime to issues more generally related to children's daily life.

After having identified the types of issues leading parents and children to engage in argumentative discussions during mealtimes, from an argumentative perspective is important to understand the specific 
contributions that they both provide to the inception of argumentation. The findings of the analysis indicate that parents and children have two distinct but equally crucial functions in the beginning phase of an argumentative discussion. To accurately reconstruct the specific role of parents and children in the inception of argumentation during mealtimes crucial is the moment at which they accept the need to defend a standpoint by providing arguments to support it. According to the model of a critical discussion, the notion of burden of proof implies that when a party advances a standpoint, she/he commits her/himself to defend her/ his position by putting forward, at least, one argument in its support. When she/he does, she/he assumes the burden of proof; when she/he does not, she/he does not accept to assume the burden of proof (van Eemeren \& Houtlosser, 2002). The investigation of the initial phase of parent-child argumentative discussions during mealtime shows that parents regularly assume the burden of proof in argumentative discussions with their children. The children, instead, often but not always, evade the burden of proof, by not being expected to provide any reasoning to support their standpoints. The following dialogue between an 8-year-old child, Marco, and his mother allows to clearly illustrate these dynamics:

\section{Excerpt 3.9}

Italian family V. Dinner 1. Family members: father (DAD, 42 years), mother (MOM, 40 years), Marco (MAR, 8 years and 6 months), and Leonardo ( 5 years and 7 months). All family members are seated at the meal table. DAD sits at the head of the meal table, MOM and LEO sit on the right-hand side of DAD, while MAR is seated on their opposite side.

1. *MAR: Mamma [:! a bassa voce]

2. *MOM: eh Mom [:! a low tone of voice]

3. *MAR: voglio parlare [:! a bassa voce] I want to talk:: [:! a low tone of voice]

$\rightarrow \quad$ *MAR: $\quad$ ma non è possibile [:! a bassa voce] but it is not possible [:! a low tone of voice]

$\rightarrow \quad$ *MAR: $\quad$ perché la mia voce è brutta [:! a bassissima voce] because my voice is bad [:! a very low tone of voice] 
4. *MOM: no assolutamente! absolutely not!

$\rightarrow \quad$ *MOM: no::

5. *MAR: $\quad$ dai:: ((col tono di chi dice una cosa evidente)) please Mom:: ((with the tone of someone who says something obvious))

6. *MOM: perché?

why?

$\rightarrow \quad$ *MOM: $\quad$ io non penso proprio.

I do not think so

$\rightarrow \quad$ *MOM: una bella voce, da uomo

a beautiful voice, [the voice] of a man

$\rightarrow \quad$ *MOM: grossa bella.

big beautiful

7. *MAR: no:

no:

8. *MOM: stasera:: se si sentirà il rumore del pane chioccarello [:! sorridendo] tonight:: if we hear the sound of crisp bread ((the noise when crisp bread is being chewed)) [:! smiling]

9. *MAR: bene, ma adesso mica fino a questo punto! fine, but not to this point!

The sequence, in line 1, begins with Marco's negative assumption ("I want to talk, but it is not possible because my voice is bad"). However, the child does not defend his initial assumption by providing arguments, refusing to assume the burden of proof since, for him, his assumption needs no defense (please Mom::). The mother, instead, provides arguments to defend her different standpoint and, therefore, accepts to assume the burden of proof. Moreover, by providing an argument in support of her standpoint, the mother assumes the decision to begin the argumentative discussion.

Despite the burden of proof is mostly on parents, children play an equally crucial argumentative role, since, through their questioning, they lead their parents to justify the reasons on which parental rules and prohibitions are based. In this regard, the Why-question asked by children to their parents appears to have an important role. The children's Why-questions appear to be a linguistic indicator of the beginning of an argumentative discussion between parents and children 
during mealtime conversations. Asking this type of question, the children challenged their parents to justify their rules and directives, which were frequently implicit or based on rules not initially known by or previously made explicit to them. During mealtime conversations, the presence of children seems to favor the beginning of argumentative discussions and represents a stimulus factor, inducing parents to reason with their children. Through the Why-questions, children manifested their desire to know the reason behind the parents' directives, and through an argumentative discussion, they try to achieve their purpose. For example, we have seen how, in Excerpt 3.8, the Why-question asked by the child, Alessandro, produces the effect of eliciting the explication of the rule on which the parental directive is based:

4. *MOM: non puoi. [:! scuotendo la testa] you cannot. [:! shakes his head]

5. *ALE: perché no?

why not?

6. *MOM: perché i bambini, devono prendere delle medicine speciali because children, have to take special medicine

$\rightarrow \quad$ *MOM: $\quad$ non possono prendere le medicine degli adulti they cannot take medicine for adults

$\rightarrow \quad *$ MOM: $\quad$ altrimenti, si sentono male. otherwise, they will get sick.

Furthermore, by asking Why-questions, children assume a waiting position before accepting or casting doubt on the parental directive. The child, Alessandro, for example, wants to know the reason why he cannot take the pills from the medicine container; by asking a Whyquestion, the child is implicitly saying to his mother: "I am waiting to hear your reasons. Only after that will I be able to evaluate if your prohibition is proper or not." Alessandro's behavior does not mean that he will decide whether to obey the mother's directive only after listening to his mother's answer. Instead, it means that Alessandro puts himself in a waiting position before deciding if the mother's directive is acceptable to him or not.

The observed dynamics characterizing the initial phase of parentchild argumentative discussions reveal that argumentation is a 
co-constructed activity in which children play a role that is equally fundamental to that of their parents. Argumentative interactions should be viewed as a bidirectional process of mutual apprenticeship (Bova \& Arcidiacono, 2017; Pontecorvo, Fasulo, \& Sterponi, 2001), where parents affect children and are simultaneously affected by them. By their mutual engagement in conflictual discussions, parents and children jointly produce and transform the social order and their positions within the family frameworks, through the formatting and sequencing of actions and their responses.

\section{References}

Arcidiacono, F. (2011). "But who said that you eat when you want and what you want?" Verbal conflicts at dinnertime and strategic moves among family members. In J. P. Flanagan \& A. M. Munos (Eds.), Family conflicts: Psychological, social and medical implications (pp. 27-52). New York, NY: Nova Science Publishers.

Arcidiacono, F., \& Bova, A. (2015). Activity-bound and activity-unbound arguments in response to parental eat-directives at mealtimes: Differences and similarities in children of 3-5 and 6-9 years old. Learning, Culture and Social Interaction, 6, 40-55.

Blum-Kulka, S. (1997). Dinner talk: Cultural patterns of sociability and socialization in family discourse. Mahwah, NJ: Erlbaum.

Bova, A. (2015). Children's responses in argumentative discussions relating to parental rules and prescriptions. Ampersand, 2, 109-121.

Bova, A., \& Arcidiacono, F. (2013). Investigating children's Why-questions: A study comparing argumentative and explanatory function. Discourse Studies, 15(6), 713-734.

Bova, A., \& Arcidiacono, F. (2014). "You must eat the salad because it is nutritious". Argumentative strategies adopted by parents and children in foodrelated discussions at mealtimes. Appetite, 73, 81-94.

Bova, A., \& Arcidiacono, F. (2015). Beyond conflicts: Origin and types of issues leading to argumentative discussions during family mealtimes. Journal of Language Aggression and Conflict, 3(2), 263-288.

Bova, A., \& Arcidiacono, F. (2017). Interpersonal dynamics within argumentative interactions: An introduction. In F. Arcidiacono \& A. Bova 
(Eds.), Interpersonal argumentation in educational and professional contexts (pp. xvii-xxii). New York: Springer.

Bova, A., \& Arcidiacono, F. (2018). Interplay between parental argumentative strategies, children's reactions, and topics of disagreement during mealtime conversations. Learning, Culture and Social Interaction, 19, 124-133.

Capaldi, E. D., \& Powley, T. L. (1990). Taste, experience, and feeding. Washington, DC: American Psychological Association.

Chouinard, M. M., Harris, P. L., \& Maratsos, M. P. (2007). Children's questions: A mechanism for cognitive development. Monographs of the Society for Research in Child Development, 72(1), 1-129.

Craven, A., \& Potter, J. (2010). Directives: Entitlement and contingency in action. Discourse Studies, 12(4), 419-442.

Delamont, S. (1995). Appetites and identities: An introduction to the social anthropology of Western Europe. New York, NY: Routledge.

Frazier, B. N., Gelamn, S. A., \& Wellman, H. M. (2009). Preschoolers' search for explanatory information within adult: Child conversation. Child Development, 80(6), 1592-1611.

Goodwin, C. (2006). Retrospective and prospective orientation in the construction of argumentative moves. Text \& Talk, 26(4-5), 443-461.

Gruber, H. (2001). Questions and strategic orientation in verbal conflict sequences. Journal of Pragmatics, 33(12), 1815-1857.

Isaacs, N. (1930). Children's "why" questions. In S. Isaacs (Ed.), Intellectual growth in young children (pp. 291-349). London: Routledge \& Sons.

Kent, A. (2012). Responding to directives: What can children do when a parent tells them what to do? In S. Danby \& M. Theobald (Eds.), Disputes in everyday life: Social and moral orders of children and young people. Sociological studies of children and youth, vol. 15 (pp. 57-84). Bingley: Emerald Group Publishing.

Loukusa, S., Ryder, N., \& Leinonen, E. (2008). Answering questions and explaining answers: A study of Finnish-speaking children. Journal of Psycholinguistic Research, 37(3), 219-241.

Ochs, E., Pontecorvo, C., \& Fasulo, A. (1996). Socializing taste. Ethnos, 61(1), $7-46$.

Piaget, J. (1929). The child's conceptions of the world. London: Routledge \& Kegan.

Pontecorvo, C., Fasulo, A., \& Sterponi, L. (2001). Mutual apprentices: The making of parenthood and childhood in family dinner conversations. Human Development, 44(6), 340-361. 
639

640

641

642

643

644

645

646

647

648

649

650

651

652

653

654

655

656

657

658

659

660

661

662

663

664

665

666

Rigotti, E., \& Greco Morasso, S. (2009). Argumentation as an object of interest and as a social and cultural resource. In N. Muller-Mirza \& A. N. Perret-Clermont (Eds.), Argumentation and education (pp. 1-61). New York, NY: Springer.

Snoeck Henkemans, A. F. (1999). Argument or explanation? Propositional relations as clues for distinguishing arguments from explanations. In F. H. van Eemeren, R. Grootendorst, J. A. Blair, \& C. A. Willard (Eds.), Proceedings of the IV ISSA Conference (pp. 757-760). Amsterdam: Sic Sat.

Snoeck Henkemans, A. F. (2001). Argumentation, explanation and causality: An exploration of current linguistic approaches to textual relations. In T. Sanders, J. Schilperoord, \& W. Spooren (Eds.), Text representation: Linguistic and psycholinguistic aspects (pp. 231-246). Amsterdam and Philadelphia: Benjamins.

Stern, W. B. (1924). Psychology of early childhood. New York, NY: Henry Holt \& Co.

Valian, V., \& Casey, L. (2003). Young children's acquisition of wh-questions: The role of structured input. Journal of Child Language, 30(1), 117-143. van Eemeren, F. H., \& Grootendorst, R. (2004). A systematic theory of argumentation: The pragma-dialectical approach. Cambridge: Cambridge University Press.

van Eemeren, F. H., \& Houtlosser, P. (2002). Strategic maneuvering with the burden of proof. In F. H. van Eemeren (Ed.), Advances in pragma-dialectics (pp. 13-28). Amsterdam and Newport News, VA: Sic Sat and Vale Press.

Walton, D. N. (2004). A new dialectical theory of explanation. Philosophical Exploration, 7(1), 71-89.

Wiggins, S., \& Potter, J. (2003). Attitudes and evaluative practices: Category vs. item and subjective vs. objective constructions in everyday food assessments. British Journal of Social Psychology, 42(4), 513-531. 


\section{Author Query Form}

Book ID: 477538_1_En

Chapter No: 3

Please ensure you fill out your response to the queries raised below and return this form along with your corrections.

Dear Author,

During the process of typesetting your chapter, the following queries have arisen. Please check your typeset proof carefully against the queries listed below and mark the necessary changes either directly on the proof/online grid or in the 'Author's response' area provided

\begin{tabular}{|l|l|l|}
\hline Query Refs. & Details Required & Author's Response \\
\hline AQ1 & $\begin{array}{l}\text { The citation 'Craven and Potter (2012)' has been changed to } \\
\text { 'Craven and Potter (2010)' to match the year in the reference } \\
\text { list. Please check and correct if necessary. }\end{array}$ & \\
\hline
\end{tabular}

